\title{
Der Opioid-Skandal
}

\section{Wie sieht in Europa die gängige Praxis in der Schmerzlinderung aus? Nationale Vertreter der zuständigen Fachgesellschaften ziehen ein erschreckendes Fazit.}

—ür Patienten mit terminalem Krebs ist zentrales Behandlungsziel und Patientenrecht die Schmerzlinderung. Gleichwohl werden Opioide in den meisten Ländern aufgrund legaler oder bürokratischer Hürden, mitunter auch mangelnder Verfügbarkeit, noch viel zu wenig eingesetzt. Eine multizentrische Arbeitsgruppe der European Society for Medical Oncology und der European Association for Palliative Care hat die Verhältnisse in 21 ost- und 20 westeuropäischen Ländern mit den WHO-Vorgaben verglichen.

Während etwa in der Türkei, Griechenland und Russland kaum Opioide verwendet werden, belegt Österreich mit über $150 \mathrm{mg}$ pro Kopf und Jahr den Spitzenplatz. Auf Platz 2 und 3 folgen Dänemark (knapp $60 \mathrm{mg}$ ) und Frankreich (etwa $45 \mathrm{mg}$ ). In Osteuropa hat sich der Verbrauch auch im letzten Jahrzehnt kaum gesteigert, in Westeuropa immerhin von 20 mg pro Kopf im Jahr 1996 auf 25 mg im Jahr 2006. Deutschland liegt mit knapp 20 mg noch unter diesem westeuropäischen Durchschnitt (Grafik).

Die Barrieren für die nicht ausreichende Verschreibung sind vielfältig: So sind die von der WHO vorgesehenen Substanzen gar nicht überall verfügbar - etwa Codein und orales Morphin. Andere Länder beschränken die Kostenerstattung oder spezifizieren eine maximale tägliche Dosis, Deutschland z. B. für Oxycodon. Darüber hinaus ist die Verschreibung eines Opioids hier auf 30 Tage beschränkt, in Österreich, Finnland, Schweden und den Niederlanden hingegen auf 90 Tage.

Fazit: Bis heute gibt es in zahlreichen europäischen Ländern formale Defizite und exzessive regulatorische Hürden, die eine angemessene Patientenbehandlung verhindern. Aus ethischer Sicht und im Sinne der Volksgesundheit müssen diese Probleme angegangen werden. be

Cherny NI et al. Formulary availability and regulatory barriers to accessibility of opioids for cancer pain in Europe: A report from the ESMO/EAPC Opioid Policy Initiative. Ann Oncol 2010; 21: 615-26.

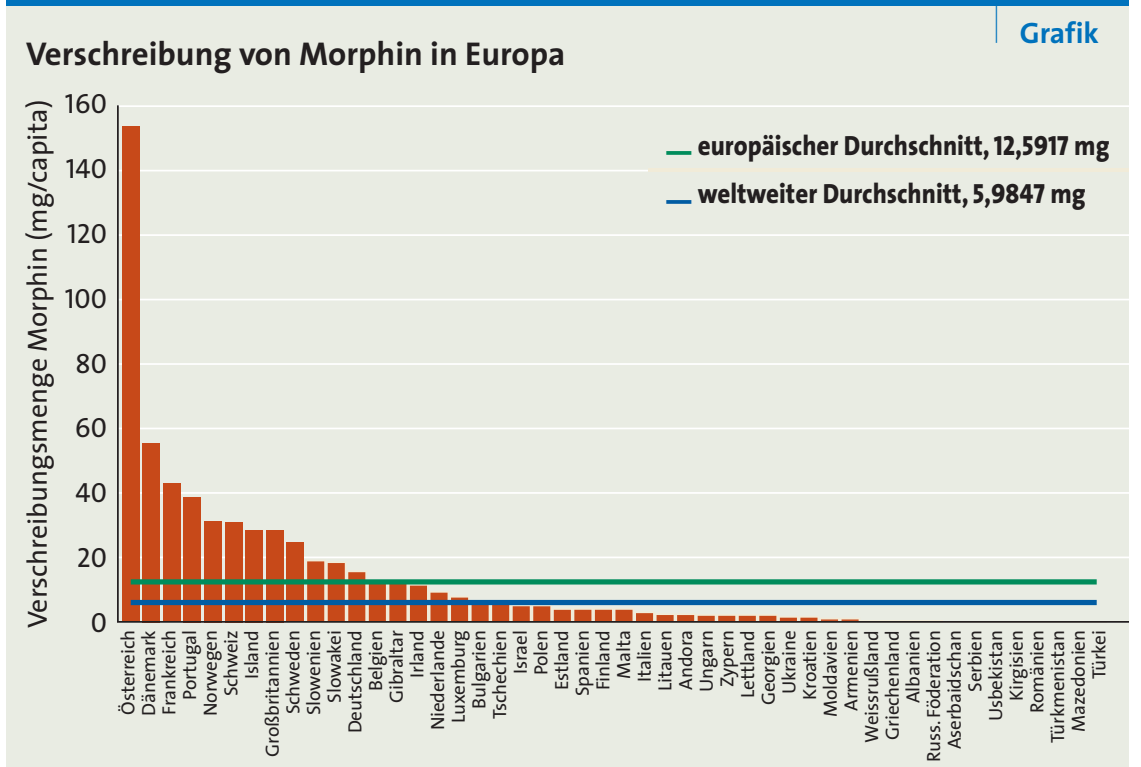

